\title{
O USO DE MATERIAIS CONCRETOS PARA ENSINAR ARITMÉTICA: SABERES PROFISSIONAIS DO PROFESSOR PRIMÁRIO (1920-1940)
}

Lidiane Gomes dos Santos Felisberto Pontifícia Universidade Católica do Paraná lidianegsfelisberto@gmail.com

\begin{abstract}
RESUMO
Considerando que o uso de materiais concretos para ensinar Aritmética integrava os saberes profissionais do professor primário, este artigo tem por objetivo identificar como o referido saber se fez presente na formação de professores no Estado do Paraná, entre 1920 e 1940. A investigação, conduzida na perspectiva da História Cultural, mobilizou fontes históricas oficiais e produções escolares de duas professorandas que cursaram o ensino normal em décadas diferentes. $\mathrm{O}$ estudo indicou que o uso de materiais concretos para ensinar Aritmética, articulados aos saberes a ensinar do $1^{\circ}$ e $2^{\circ}$ ano do ensino primário, era um saber profissional valorizado e que, na medida em que novas concepções de ensino foram sendo apropriadas, o referido saber passou por transformações, ganhando novos significados.
\end{abstract}

Palavras-chave: História da Educação Matemática. Saber Profissional do Professor. Materiais Concretos.

\section{THE USE OF CONCRETE MATERIALS TO TEACH ARITHMETICS: PRIMARY TEACHER PROFESSIONAL KNOWLEDGE (1920-1940)}

\begin{abstract}
Considering that the use of concrete materials to teach Arithmetic integrated the professional knowledge of the primary teacher, this article aims to identify how this knowledge was present in the training of teachers in the State of Paraná, between 1920 and 1940. The research, conducted in the perspective of Cultural History, mobilized official historical sources and school productions of two professors who attended normal education in different decades. The study indicated that the use of concrete materials to teach Arithmetic, articulated to the knowledge to be taught in the 1st and 2nd year of primary education, was a valuable professional knowledge and that, as new conceptions of teaching were appropriated, knowledge underwent transformations, gaining new meanings.
\end{abstract}

Keywords: History of Mathematics Education. Knowing Teacher's Professional. Concrete Materials. 


\section{EL USO DE MATERIALES CONCRETOS PARA LA ENSEÑANZA DE ARITMÉTICOS: CONOCIMIENTOS PROFESIONALES PARA PROFESORES DE PRIMARIA (1920- 1940)}

\section{RESUMEN}

Teniendo en cuenta que el uso de materiales concretos para enseñar Aritmética integró el conocimiento profesional del maestro de primaria, este artículo pretende identificar cómo este conocimiento estuvo presente en la capacitación de maestros en el estado de Paraná, entre 1920 y 1940. La investigación, realizada en La perspectiva de la Historia Cultural, movilizó fuentes históricas oficiales y producciones escolares de dos profesores que asistieron a la educación normal en diferentes décadas. El estudio indicó que el uso de materiales concretos para enseñar aritmética, articulados a los conocimientos que deben enseñarse en el primer y segundo año de educación primaria, se consideraba valioso conocimiento profesional y que, a medida que se apropiado las nuevas concepciones de la enseñanza, el conocimiento sufría transformaciones. ganando nuevos significados.

Palabras clave: Historia de la Educación Matemática. Saber Profesional del Profesor. Materiales Concretos.

\section{L'UTILISATION DE MATÉRIAUX PALPABLES POUR ENSEIGNER L'ARITHMÉTIQUE: LES CONNAISSANCES PROFESSIONNELLES DES ENSEIGNANT DU PRIMAIRE (1920-1940)}

\section{RÉSUMÉ}

Considérant que l'utilisation de matériels concrets pour enseigner l'arithmétique a intégré les connaissances professionnelles de l'enseignant primaire, cet article vise à identifier comment ces connaissances étaient présentes dans la formation des enseignants dans l'État de Paraná, entre 1920 et 1940. En perspective de l'histoire culturelle, ont été utilisées des sources historiques officielles et les productions scolaires de de deux enseignants qui ont fréquenté l'école normale, dans différentes décennies. L'étude indiquait que l'utilisation de matériel concret pour enseigner l'arithmétique, articulée autour des connaissances à enseigner au cours de la première et de la deuxième années de l'enseignement primaire, a été considéré un savoir professionnel précieux et que, dans la mesure où de nouvelles conceptions de l'enseignement ont été appropriées, les connaissances professionnelles de l'enseignant a transformé et acquérir de nouvelles significations.

Mots-clés: Histoire de l'enseignement des Mathématiques. Savoir professionnelles de l'enseignant. Matériaux palpables.

\section{INTRODUÇÃO}




\section{$(\mathrm{cc})$ EY}

Pesquisas relacionadas à formação de professores têm indicado que o saber profissional do professor se constitui em um conjunto de conhecimentos que articula tanto saberes disciplinares, quanto saberes específicos para o exercício docente. Estes saberes, caracterizados por Hofstetter e Schneuwly (2017) como a e para ensinar, respectivamente, tem permitido que estudos no campo da História da Educação Matemática avancem no sentido de compreender os movimentos de constituição "dos saberes profissionais dos professores que ensinam matemática" (VALENTE, 2018, p. 197).

Em perspectiva histórica, focando na Aritmética ensinada nos primeiros anos da escola primária brasileira, percebe-se, desde o final do século XIX com a vulgarização do método intuitivo, que o ensino se efetivou, principalmente, por meio de materiais concretos, sendo eles considerados importantes para a aprendizagem matemática. Investigar que concepção de concreto norteou o ensino de Aritmética tem sido objeto de estudo dessa autora há cerca de sete anos, porém, diante do referencial teórico-metodológico dos saberes, a questão do concreto, mais especificamente, do uso dos materiais no ensino, tem provocado novos questionamentos. Dentre eles: O "saber utilizar o concreto para ensinar matemática" trata-se de um saber profissional do professor? Em qual categoria este saber se enquadra? Este saber se fez presente na formação de professores primários? É possível, diante dos movimentos e reformas implantadas na Educação, identificar transformações neste saber?

Considerando que dentro da cultura escolar o professor é um sujeito ativo e que de maneira criativa coloca em funcionamento as regras (JULIA, 2001), é possível considerar que o sucesso do manejo destes materiais estava subordinado ao professor, o qual determinava, em sala de aula, quando e como os materiais seriam utilizados. Partindo da ideia de que o saber utilizar os materiais concretos para ensinar Aritmética encontrava-se no conjunto dos saberes profissionais do professor primário, este artigo, pelo viés da História Cultural, tem por objetivo identificar como este saber se fez presente na formação de professores no Estado do Paraná, entre as décadas de 1920 e 1940.

\section{O ENSINO NORMAL NO PARANÁ NA DÉCADA DE 1920}

A formação de professores primários, por meio do ensino normal, durante o período investigado, passou por diferentes reformas. Sobretudo, o que essas reformas indicam é que elas 


\section{$(\mathrm{cc})$ EY}

estavam por requerer espaço para matérias que fossem capazes de transmitir saberes competentes ao exercício da profissão docente.

A chegada de São Paulo do professor César Prieto Martinez ao Paraná, em 1920, para assumir o cargo de Inspetor Geral da Instrução Pública, fez com que a formação de professores primários ganhasse cuidado por parte do governo, uma vez que Martinez a compreendia como determinante do "bom ou mau êxito de todo o aparelho escolar" por fornecer "o material mais importante, que é o professor" (PARANÁ, 1920, p. 16).

Uma das primeiras ações realizadas por Martinez, nesse aspecto, foi a separação da Escola Normal do Ginásio Paranaense, pois, segundo ele, "sendo diferente a missão de cada estabelecimento, com programa diverso, não se justificava que as aulas fossem dadas em conjunto" (PARANÁ, 1920, p. 15). A partir daí, o programa foi mudado, dando mais ênfase às matérias que pudessem munir o professor com os saberes necessários para desenvolver suas funções na escola primária. Entre as matérias do programa foram acrescentadas: Antropologia Pedagógica, com a finalidade de que o professor conhecesse a natureza infantil bem como "os característicos somáticos segundo os quais o educando é reconhecido e classificado para receber do preceptor os cuidados pela sua natureza" (PARANÁ, 1920, p. 16); Psicologia Infantil, que forneceria conhecimentos para que o professor pudesse encaminhar o trabalho pedagógico visando a formação física, intelectual e moral dos alunos; História da Pedagogia e Metodologia Geral, nas quais se estudaria a natureza dos métodos e como ensinar as matérias em todas as classes.

No ano de 1922 a Escola Normal ganhou um prédio próprio e no ano seguinte Lysímaco Ferreira da Costa, diretor da referida instituição, publicou as "Bases Educativas para a Organização da Nova Escola Normal Secundária do Paraná" (PARANÁ, 1923), documento que implantou uma reforma na formação de professores primários, cujo objetivo era "formar um professor bem preparado para o exercício das suas funções” (PARANÁ, 1923, p. 9).

Um dado importante, implantado por meio do documento acima citado, foi a reorganização do programa do ensino normal, a qual separou os estudos em curso geral e especial. O curso geral, com duração de três anos, tinha por objetivo "preparar a cultura geral do futuro professor" (PARANÁ, 1923, p. 15), enquanto que o curso especial, ofertado em um ano e meio, objetivava dar "uma boa técnica metodológica, apoiada nos princípios gerais e regras da Pedagogia" (PARANÁ, 1923, p. 19). 


\section{$(\mathrm{cc}) \mathrm{BY}$}

O curso especial, de caráter instrumental à ação docente, estava assim organizado:

No $1^{\circ}$ semestre: Psicologia, com 6 aulas semanais, e metodologia geral, metodologia da leitura e escrita, metodologia do desenho, agronomia e higiene. No $2^{\circ}$ semestre: Moral e educação cívica, sua metodologia, Noções de Direito Pátrio e de legislação escolar; metodologia do vernáculo; metodologia da aritmética; metodologia do ensino intuitivo; metodologia das ciências naturais; metodologia da geografia. No $3^{\circ}$ semestre: Puericultura; metodologia da história; metodologia da geometria; metodologia da música; metodologia dos exercícios físicos; metodologia dos trabalhos manuais; prática e crítica pedagógicas. (PILOTTO, 1954, p. 93).

Embora o rol de matérias ministradas no curso especial não permita identificar o saber profissional relacionado ao uso de materiais concretos no ensino de Aritmética, as Bases Educativas apontam que uma das funções do professor, a qual a Escola Normal se encarregaria de ensinar, tratava-se de saber "transmitir um conhecimento novo e, sobretudo, não vacilar no cumprimento dos programas de ensino" (PARANÁ, 1923, p. 9).

Indo ao programa de Aritmética do ensino primário em vigor, "Programa dos Grupos Escolares do Estado do Paraná" (PARANÁ, 1921), constata-se o indicativo para o uso de materiais para ensinar alguns conteúdos matemáticos do $1^{\circ}$ e $2^{\circ}$ ano:

QUADRO 1 - Conteúdos de Aritmética no programa de 1921.

\begin{tabular}{|l|l|}
\hline & a) Rudimentos das primeiras operações com cálculos concretos, \\
& servindo-se o aluno de tornos, palitos, taboinhas, etc. \\
& b) Conhecimento direto dos grupos - 2,3,4,5, etc. por um simples \\
golpe de vista e sem contar. \\
c) Somma direta de objetos de $1 \mathrm{em} 1$, de $2 \mathrm{em} 2$, de $3 \mathrm{em} \mathrm{3,} \mathrm{etc.} \mathrm{até}$ \\
20 e contagem de 10 em 10 até 100. \\
d) Exercícios sobre as quatro operações até 100. \\
e) Leitura e escrita de números e uso dos sinais praticados nas \\
quatro operações. \\
f) Exercícios orais e escritos sobre os cálculos da carta de Parker, \\
inclusive exercícios sobre frações. \\
g) Estudo das quatro operações até 100, do modo mais concreto \\
possível. Problemas ao alcance do raciocínio infantil. \\
h) Conhecimento dos algarismos romanos. O relógio. \\
i) Conhecimento prático do metro, litro e quilo. \\
j) Leitura das cartas de Parker. \\
\hline $2^{\circ}$ ano & a) Estudo prático da numeração oral e escrita até milhar. Estudo \\
\hline
\end{tabular}

Rev. Iberoam. Patrim. Histórico-Educativo, Campinas (SP), v. 5, p.1-19, e019030, 2019. 


\begin{tabular}{|l|l|}
\hline prático da formação de unidades, dezenas, centenas e milhares. \\
b) Cálculo mental de acordo com as lições das cartas de Parker, \\
incluindo frações. \\
c) Continuação dos algarismos romanos. \\
d) Taboada de multiplicar até 10, por meio de tornos. \\
e) Leitura das cartas de Parker. \\
f) Estudo elementar completo das 4 operações fundamentais até \\
milhares. Exercícios práticos. \\
g) Conhecimento das unidades principais de comprimento, \\
superfície, capacidade e peso. Exercícios práticos \\
correspondentes. \\
h) Conhecimento da moeda brasileira.
\end{tabular}

Fonte: Paraná, 1921, grifo nosso.

As instruções específicas para o ensino de Aritmética, presentes no referido Programa, indicam que o cálculo concreto deveria ser "o início da classe nas quatro operações por meio de tornos, palitos ou pequenos objetos" (PARANÁ, 1921, p. 25). Sendo assim, no $1^{\circ}$ ano, especificamente, o professor deveria dividir a turma em três classes (A, B, e C) de acordo com o grau de adiantamento e encaminhar atividades de cálculo, revezando entre as classes o cálculo concreto (com o uso de objetos) e o cálculo escrito. Já no $2^{\circ}$ ano, o Programa recomendava para que, gradativamente, o ensino fosse perdendo a feição concreta. Além disso, o uso das Cartas de Parker" era reiterado: “É vantajoso que o professor acompanhe, nesse ensino, as cartas de Parker, podendo desde logo iniciar a sua classe na leitura delas" (PARANÁ, 1921, p. 25).

No fato da Escola Normal ter uma matéria denominada Metodologia de Aritmética e a incumbência de preparar o professor para "não vacilar no cumprimento dos programas" (que indicavam materiais para ensinar), têm-se os vestígios de que o uso de materiais concretos para ensinar Aritmética se fazia presente na formação de professores, integrando o conjunto dos saberes profissionais do professor primário.

$1 \mathrm{O}$ referido material didático auxiliava no ensino das quatro operações fundamentais e contrapunha-se ao ensino pela memorização por não seguir uma lógica linear e sequencial (VALENTE, 2008). As cartas de Parker davam ao ensino um caráter intuitivo, pois iniciando pelo uso de materiais concretos, fazia com que o aluno se apropriasse primeiro da ideia ou conceito matemático, para em seguida avançar à palavra ou conceito (FELISBERTO, 2014). Segundo Valente (2008), as cartas se fizeram presentes no método intuitivo e foram suportes para o ensino ativo, característico da Escola Nova.

Rev. Iberoam. Patrim. Histórico-Educativo, Campinas (SP), v. 5, p.1-19, e019030, 2019. 


\section{A ESCOLA DE PROFESSORES DE CURITIBA}

Avançando ao ano de 1937, a formação de professores no Paraná passou novamente a ser discutida a fim de atender aos novos regulamentos que estavam sendo ministrados pelo Governo Federal.

Na Mensagem de Governo, proferida à Assembleia Legislativa do Paraná, Manoel Ribas comunicou que havia ocorrido uma remodelação no curso de especialização pedagógica com a criação das Escolas de Professores "para o aperfeiçoamento técnico-cultural do magistério" (PARANÁ, 1937, p. 32).

Conforme o boletim do INEP, “Organização do Ensino Primário e Normal - XV - Estado do Paraná", de 1942, poderiam se matricular nas Escolas de Professores alunos que tivessem concluído os cinco anos do Curso Secundário ou o curso geral da extinta Escola Normal. A formação de professores se dava em dois anos e contemplava estudos técnico-pedagógicos necessários ao exercício da docência (BRASIL, 1942).

O programa de ensino da Escola de Professores estava assim organizado:

QUADRO 2 - Programa do Curso Normal das Escolas de Professores.

\begin{tabular}{|c|c|c|}
\hline \multirow{2}{*}{$1^{\circ}$ ano } & $1^{\mathrm{a}}$ seção & $\begin{array}{l}\text { Psicologia geral e infantil; } \\
\text { Pedagogia Geral; } \\
\text { Metodologia e prática do ensino; } \\
\text { História da Educação. }\end{array}$ \\
\hline & $2^{\mathrm{a}}$ seção & $\begin{array}{l}\text { Metodologia e prática do ensino; } \\
\text { Biologia aplicada à educação; } \\
\text { Puericultura; } \\
\text { Higiene Escolar. }\end{array}$ \\
\hline \multirow[b]{2}{*}{$2^{\circ}$ ano } & $3^{\mathrm{a}}$ seção & $\begin{array}{l}\text { Metodologia e prática do ensino; } \\
\text { Sociologia geral; } \\
\text { Sociologia educacional. }\end{array}$ \\
\hline & $4^{\mathrm{a}}$ seção & $\begin{array}{l}\text { Metodologia e prática do ensino; } \\
\text { Desenho, modelagem e caligrafia; } \\
\text { Trabalhos Manuais; } \\
\text { Música e canto orfeônico; } \\
\text { Noções fundamentais de agronomia; } \\
\text { Educação Física; } \\
\text { Educação Doméstica. }\end{array}$ \\
\hline
\end{tabular}


Fonte: Brasil, 1942, grifo nosso.

O Decreto n. 6150 de 10 de janeiro de 1938 determinava que anexo a cada Ginásio do Estado deveria funcionar uma Escola de Professores e, a estas, uma Escola de Aplicação para que os normalistas pudessem aplicar os conhecimentos adquiridos por meio da prática de ensino em classes de jardim de infância e do ensino primário (BRASIL, 1942).

Embora que em âmbito nacional o estabelecimento do Estado Novo e a promulgação da Constituição de 1937 tivessem freado as ações decorrentes do Movimento da Escola Nova, fazendo com que as lutas entrassem em um período de hibernação, os reformadores escolanovistas "continuaram a lutar no terreno da ação pessoal” (ROMANELLI, 1998, p. 154). No caso do Paraná, Erasmo Pilotto, na direção da Escola de Professores de Curitiba, foi o expoente paranaense (talvez expert?) que levantou a bandeira da Escola Nova e tornou a referida instituição como espaço privilegiado de aplicação da nova Pedagogia.

Nesse sentido, Miguel (2011) considera que o período de 1938 a 1946 foi o momento de consolidação das ideias da Pedagogia da Escola Nova no Paraná pelas experiências vividas na referida instituição. Segundo a autora,

A percepção da Pedagogia como ciência com estatuto próprio permeava a proposta da Escola de Professores e era entendida como o modo de aprofundar, observar e sistematizar os conhecimentos específicos de uma área educacional: Sociologia, Biologia ou Psicologia. Mas representava, principalmente, o estudo de métodos baseados na observação e experimentação que iriam direcionar com maior segurança a ação profissional do professor, tanto na transmissão dos conhecimentos aos alunos como na ação educacional junto à comunidade onde a escola na qual fosse atuar estivesse localizada. (MIGUEL, 1997, p. 83).

A Escola de Professores de Curitiba tinha como função formar professores primários; ser um centro de cultura pedagógica, com investigação filosófica e investigação experimental relativa à educação; bem como, ser o centro de vulgarização pedagógica (MIGUEL, 2011). Conforme Erasmo Pilotto (1954), o seu objetivo frente à Escola de Professores era de fornecer tanto a formação prática como os fundamentos teóricos necessários ao exercício da profissão docente. Em suas palavras:

Desdobra-se a nossa atividade em dois campos, num procurando-se a formação prática, eminentemente prática dos alunos, e noutro procurando-se pô-los em contacto com os Princípios, com as Ideias Gerais, ao mesmo tempo que 
procurando familiarizá-los com tudo que signifique o exercício das suas faculdades de criação e liberação. (PILOTTO, 1954, p. 96).

Quando Erasmo Pilotto assumiu o cargo de Secretário de Educação e Cultura do Estado do Paraná, a partir de 1948, buscou vulgarizar as práticas desenvolvidas na Escola de Professores de Curitiba. Dentre suas ações, incentivou a criação do Centro de Estudos e Pesquisas Educacionais (CEPE), elaborou o Anteprojeto da Lei Orgânica da Educação (1949) e participou da comissão que elaborou os Programas Experimentais, publicado em 1950 (FELISBERTO, 2019).

Reunindo os vestígios da formação de professores deste período, - como a defesa de processos pedagógicos ativos, a prática desenvolvida na Escola de Aplicação, a presença constante de "Metodologia e prática de ensino" no curso normal, bem como a revisão dos programas primários que ocorria na referida matéria (PARANÁ, 1949) - tudo leva a crer que o saber profissional relacionado ao uso de materiais concretos para ensinar Aritmética fazia-se presente na formação de professores. Conforme Felisberto (2019), era na matéria de "Metodologia e prática de ensino" que a concepção de concreto era transmitida, fazendo com que este saber para ensinar Aritmética no ensino primário se tornasse $a$ ensinar no contexto de formação.

A partir do programa do ensino primário em vigor, publicado em 1932 e reimpresso em 1940 com pequenas alterações, constata-se que o uso de materiais no ensino de Aritmética continuava prescrito na legislação escolar do $1^{\circ}$ e $2^{\circ}$ ano, inclusive as Cartas de Parker. As orientações contidas nos programas indicavam que o ensino de Aritmética deveria ser "intuitivo, prático e o mais concretizado possível" (PARANÁ, 1932, p. 38; PARANÁ, 1940, p. 36), bem como "essencialmente concreto e experimental" (PARANÁ, 1932, p. 59; PARANÁ, 1940, p. 52), visando a aplicação e a utilidade do conhecimento matemático na vida cotidiana.

É importante salientar que mesmo que os programas do ensino primário paranaense estivessem atendendo alguns princípios defendidos pela Escola Nova, como o ensino gradual e experimental, ainda assim estavam distantes do que os educadores reformistas consideravam como ideal. Na década de 1940, a formação de professores e as escolas primárias do Paraná, segundo Trindade e Andreazza, andavam descompassadas, já que enquanto a Escola de Professores buscava "divulgar tudo o que havia de renovador na área da Educação" 
(c) $)$ EY

(TRINDADE; ANDREAZZA, 2001, p. 105), para o ensino primário fora aprovado um programa “disciplinador e normativo, com caráter conservador" (TRINDADE; ANDREAZZA, 2001, p. $105)$, condizentes com o regime político em vigor.

Ao que tudo indica, a publicação dos Programas experimentais para o ensino primário (PARANÁ, 1950), com característica dos programas mínimos, foi um dos fatores que minimizou o distanciamento entre as práticas desenvolvidas na formação de professores e na escola primária

Com relação ao uso dos materiais concretos para ensinar Aritmética, pode ser observado que o referido programa passou a valorizar não apenas os objetos, mas as situações que o ambiente proporcionava. Para o $1^{\mathrm{o}}$ ano, por exemplo, os Programas experimentais sugeriam práticas ao professor com atividades como: a) mostrar certa quantidade e solicitar aos alunos para colocarem sobre a mesa a mesma quantidade de palitos ou dedos; b) produzir sons por meio de batidas e pedir para que os alunos reproduzissem o número de batidas com palmas ou batendo em outro objeto; c) contar os alunos conforme fossem chegando à sala, fazendo menção do primeiro e o último a chegar; d) realizar comparações entre o número de meninas e de meninos; e) fazer operações a partir da relação de alunos presentes em sala e os que haviam faltado; f) disponibilizar grande quantidade de grãos de milho ou palitos para que os alunos separassem de 10 em 10; g) solicitar que os alunos distribuíssem palitos conforme o número indicado ou que classificassem objetos por quantidade e cor; etc. (PARANÁ, 1950).

Conforme as análises dos documentos oficiais, apesar das mudanças ocorridas na educação paranaense, o uso de materiais concretos para ensinar Aritmética, associado aos saberes $a$ ensinar do $1^{\circ}$ e $2^{\circ}$ ano, foi uma permanência no período investigado. Como apontam os vestígios, era também um saber trabalhado na formação de professores. O que outras fontes teriam a revelar?

\section{A ARITMÉTICA PARA ENSINAR: VESTÍGIOS DA FORMAÇÃO DE PROFESSORES}

Conforme Valente (2018), investigar o saber profissional pelo viés histórico implica na problemática dos processos e dinâmicas de constituição desse saber, o que leva a revelar como cada tempo histórico-pedagógico sedimentou ideários e consensos. Neste sentido, quais as ideias a respeito do uso de materiais concretos para ensinar Aritmética estavam consolidadas? Quais os processos e as dinâmicas presentes na constituição desse saber? Houve, por meio da consolidação

Rev. Iberoam. Patrim. Histórico-Educativo, Campinas (SP), v. 5, p.1-19, e019030, 2019. 


\section{$(\mathrm{cc})$ EY}

da Pedagogia da Escola Nova na Escola de Professores de Curitiba, mudanças em relação a essas ideias?

$\mathrm{Na}$ perspectiva da História Cultural, é o diálogo estabelecido entre as fontes que possibilita ao pesquisador aproximar-se das práticas de tempos passados. Mais do que apenas identificar, no tempo e espaço delimitado, a presença do saber profissional investigado, inquieta conhecer sobre como este saber era transmitido, que concepções fundamentavam-no. Neste sentido, apenas as legislações não foram suficientes para revelar tais detalhes, por isso, são apresentadas a seguir produções de ex-alunas que vivenciaram as duas reformas no ensino normal paranaense, apresentadas anteriormente.

Na revista "O ensino" de 1924 encontra-se uma seção denominada "Methodologia de Mathematica" na qual uma professoranda da Escola Normal, Aydée Nicleves, descreveu sobre como ensinar a adição no $1^{\circ}$ ano escolar. Na introdução de seu texto, Nicleves (1924) discorreu sobre os aspectos gerais que deveriam nortear o ensino, como o fato do professor precisar dar atenção especial à Matemática, ser compreensível aos alunos e tornar o ensino objetivo, racional e graduado.

Segundo Nicleves, antes de iniciar o ensino da adição o professor deveria examinar os conhecimentos que os alunos possuíam em relação à quantidade e, para isso, diferentes materiais poderiam ser utilizados: "apresentando-se-lhes diversas coisas, - lápis e palitos, por exemplo, pedirá o professor que lhe tragam 3, 5, 7, 8, 910 dessas coisas" (NICLEVES, 1924, p. 152). Em seguida, deveria ser explorada a noção de numeração decimal, na qual também se recomendava o uso de materiais: "Para melhor ser compreendido o mecanismo das dezenas e centenas o professor arranjará dez grupos de dez taboinhas ou palitos, para que as crianças, por si, repitam a lição e verifiquem com os próprios olhos a verdade ensinada" (NICLEVES, 1924, p. 154).

O ensino da adição seria, de início, conduzido pelas Cartas de Parker e, posteriormente, o professor deveria exemplificar que a adição refere-se ao resultado total de unidades, dezenas e centenas (NICLEVES, 1924).

Tomando o manual "Primeiras Lições de Coisas" (CALKINS, 1950)², material destinado a ensinar os professores primários a utilizar o método intuitivo, verifica-se que as recomendações de Nicleves (1924) são semelhantes às de Calkins (1950) que orientava ao professor se certificar do ponto de partida, buscando identificar as noções matemáticas que os alunos possuíam. Nesse

2 O referido manual, traduzido e publicado em língua portuguesa em 1886 por Rui Barbosa, esteve em circulação no estado do Paraná e foi apropriado pela legislação escolar na década de 1910 (PINTO; FELISBERTO, 2016). 


\section{$(\mathrm{cc})$ EY}

sentido, Calkins (1950) recomendava que antes de iniciar as primeiras lições de número, o professor reunisse vários objetos para serem utilizados, como lápis, moedas, botões, maçãs, livros, entre outros.

Outro elemento do ensino de Matemática apontado por Nicleves, "o ensino objetivo tanto quanto possível” (1924, p. 152), também pode ser encontrado entre as orientações dadas por Calkins:

O sistema de ensino objetivo enceta a instrução preliminar das crianças, nesta matéria, provocando a experiência pessoal dos alunos a respeito das relações numéricas das coisas, e levando o espírito infantil a perscrutar em vários sentidos essas propriedades delas. Foge-se a formas abstratas, enquanto os discípulos não se familiarizarem com as diversas combinações de objetos, sobre o que ela há de estribar. (CALKINS, 1950, p. 323-324).

O conjunto destas fontes indica vestígios de que o uso dos materiais concretos para ensinar Aritmética, na década de 1920 no Paraná, estava, sobretudo, atrelado às concepções de ensino do método intuitivo.

O artigo de Nicleves (1924) vem mostrar que a ideia de que os objetos deveriam ser recursos utilizados para ensinar matemática no início da escolarização, além de ser uma representação presente na legislação educacional do Estado, era uma ideia apropriada na formação de professores, uma vez que se pressupõe que estes conhecimentos tenham sido adquiridos por Nicleves na Escola Normal. De outro modo, o espaço ocupado por este ideário em um periódico pedagógico sinaliza para o consenso de que este era um saber importante ao professor primário.

Avançando à década de 1940, a segunda fonte, produzida na Escola de Professores de Curitiba, trata-se de um caderno de Metodologia de 1945, da ex-aluna Zilá Fernandes. Como pode ser observado no Quadro 2, a matéria de 'Metodologia e prática do ensino' ocupava um espaço significativo entre as matérias do ensino normal.

Nas primeiras páginas do caderno de Fernandes (1945) foram registrados conteúdos gerais acerca da didática e da metodologia de ensino. Em um segundo momento, iniciaram os registros das metodologias específicas das matérias do ensino primário.

Referente à Aritmética, já de início, foi registrado que esta era "uma das mais fáceis e interessantes matérias da escola primária” (FERNANDES, 1945, p. 62-63). O texto, além de atrelar o sucesso de ensinar a Aritmética ao conhecimento do professor sobre a psicologia 


\section{$(\mathrm{cc})$ EY}

infantil, citava Thonrdike ${ }^{3}$ o qual afirmava que a matéria "poderia ser considerada como um jogo em si mesma” (FERNANDES, 1945, p. 63).

Estes primeiros registros sobre a Aritmética justificam o encaminhamento dado a seguir. Todos os conteúdos, desde a noção de número até o ensino da multiplicação (quando se encerraram as folhas do caderno), foram abordados a partir da indicação de materiais, jogos e exercícios que os professores poderiam utilizar para ensinar. A princípio, foram apresentados os jogos de Decroly, pois conforme os registros do caderno, esses exploravam as noções mais elementares e poderiam ser utilizados ainda no jardim de infância. Depois, Maria Montessori, suas recomendações e seus materiais para o ensino.

Assim como recomendado por Nicleves (1924), o registro no caderno de Fernandes (1945) alertava para que o professor não iniciasse o ensino por um ponto muito alto do que a criança pudesse acompanhar. Nesse sentido, o texto do caderno, indicando jogos e exercícios de Decroly, orientava para que no início fossem trabalhadas as noções de presença e ausência (mostrando e escondendo objetos para a criança encontrar); discriminação e identificação (a partir da classificação de objetos de acordo com categorias); a noção de número e algarismo (com jogos de pequenos cartões); e a noção de série (com uso de objetos e fitas para serem organizados pelas crianças). Na sequência, materiais de Montessori foram citados para o ensino da contagem, da representação dos números, da associação do algarismo à quantidade, para desenvolver a noção de zero e a leitura inteligente dos números (FERNANDES, 1945). Somente depois que a criança tivesse dominado o conceito de número, sendo capaz de relacionar a quantidade ao algarismo, o professor poderia avançar ao ensino das operações aritméticas (FERNANDES, 1945).

Dando atenção à adição, que foi abordada no texto de Nicleves (1924), o ensino, segundo o caderno de Fernandes (1945), deveria se dar pela exploração do material de barras de Montessori, que consistia em barras de diferentes tamanhos que representavam os números de 1 a

3 Edward Lee Thorndike foi professor norte-americano e atuava na Universidade de Columbia (THORNDIKE, 1936). Foi autor de manuais pedagógicos referentes ao ensino de Matemática e teve ampla circulação no Brasil. Para ele, a atividade mental e a busca por resultados, exigidos pela Aritmética, eram fatores que gerava um interesse (quase natural) na criança. O professor, conhecendo a psicologia infantil, deveria usar de algumas estratégias para ensinar Aritmética: "O trabalho se tornará mais interessante para a criança, na medida em que implicar em ação física e variedade, desenvolver-se numa situação de sociabilidade, oferecer uma oportunidade de vitória, um proveito prático, relacionar-se com alguém ou alguma cousa de que goste e, acima de tudo, talvez, se se prestar a consecução de uma finalidade, de um objetivo que, no momento, esteja desempenhando papel importante em sua vida" (THORNDIKE, 1936, p. 37). 


\section{$(\mathrm{cc})$ EY}

10. O uso do material tinha como objetivo trabalhar a noção de adição, sem necessariamente tratar da operação (FERNANDES, 1945).

Para o primeiro exercício relacionado à noção de adição, o professor deveria apresentar a barra de número 10 e solicitar, como em forma de desafio aos alunos, para que com as outras barras eles formassem o 10. Por meio deste exercício, de juntar barras, os alunos poderiam formar mais quatro barras de 10, unindo 9 e 1; 8 e 2; 7 e 3; 6 e 4. Os registros do caderno vão indicando possíveis diálogos que o professor poderia manter com os alunos no desenvolvimento da atividade. O caso da subtração, trabalhado em seguida, poderia ser ensinado com o mesmo material, neste caso, o professor solicitaria aos alunos para "desmanchar o 10", separando as peças: $10-1=9$ (FERNANDES, 1945).

Considerando que o inconveniente da continuidade do processo da adição estava no volume de material, o caderno apontava como sugestão o uso de um material feito de fios de arames flexíveis ou do contador. Por meio destes outros materiais seria possível trabalhar a contagem de altos números, a numeração decimal e as operações. Além disso, era recomendado que o uso desses materiais fosse acompanhado pelos registros em folha, assim, as trocas das casas decimais seriam realizadas concretamente.

O que o caderno de Fernandes (1945) vem indicar, em relação ao texto de Nicleves (1924), é que o saber profissional concernente ao uso de materiais concretos para ensinar Aritmética passou por transformações. Se no primeiro momento foi possível identificar a orientação do ensino intuitivo, no segundo momento, o encaminhamento das atividades orientadas pelo professor em forma de desafio ou sugestão, parece que possibilitavam maior atividade do aluno no manuseio dos materiais, o que corresponde aos princípios defendidos pela Pedagogia da Escola Nova. Por outro lado, o fato de que todos os conteúdos de Metodologia de Aritmética fossem trabalhados a partir de materiais para ensinar, revela que o saber profissional investigado era considerado importante na formação de professores, servindo como um fio condutor para o ensino das noções e operações matemáticas, reiterando a articulação entre os saberes $a$ e para ensinar.

\section{AS TRANSFORMAÇÕES IDENTIFICADAS NO SABER PROFISSIONAL DO PROFESSOR}




\section{$(\mathrm{cc}) \mathrm{BY}$}

De acordo com Piaget, o método intuitivo estava mais voltado para a figuração do ensino do que para a construção ativa do conhecimento:

Os métodos intuitivos conseguem simplesmente fornecer aos alunos as representações imagéticas falantes, seja dos objetos ou acontecimentos, seja do resultado das possíveis operações, mas sem conduzir a uma realização efetiva daqueles. Tais métodos, aliás clássicos, renascem sem cessar das próprias cinzas e constituem, na verdade, um progresso em relação aos processos puramente verbais ou formais do ensino. Mas de modo algum são suficientes para desenvolver a atividade operatória. (PIAGET, 2010, p.93).

No texto de Nicleves (1924) pode-se perceber que os materiais concretos não estavam a serviço da atividade operatória dos alunos, mas tinham por objetivo possibilitar a repetição da lição para que fosse possível da criança observar as relações estabelecidas: "Para melhor ser compreendido o mecanismo das dezenas e centenas o professor arranjará dez grupos de dez taboinhas ou palitos, para que as crianças, por si, repitam a lição e verifiquem com os próprios olhos a verdade ensinada" (NICLEVES, 1924, p. 154, grifos nossos).

Já pelo caderno de Fernandes (1945), os vestígios da apropriação das ideias de Decroly e Montessori não apenas indicam a presença da Escola Nova, como também, as explicações direcionavam para práticas de ensino diferentes daquelas identificadas anteriormente.

Valorizando os estudos referentes à psicologia infantil, o caderno de Fernandes (1945) aponta que os normalistas eram ensinados, a partir de materiais concretos, a provocar os alunos (motivá-los) para descobrir as relações matemáticas possíveis entre os objetos. Observa-se que a ênfase inicial recai sobre desenvolver as noções matemáticas, sem preocupações eminentes com nomenclaturas ou registros no caderno.

Evidentemente que o intuitivo não foi negligenciado nas práticas de ensino. Seus atributos, como o de apresentar representações imagéticas, continuou fazendo parte do processo de ensino, mas o sentido dado para essas representações ganhou outro significado na medida em que se passou a valorizar a atividade dos alunos e, consequentemente, a requerer a reflexão deles sobre suas próprias ações. Nas sugestões práticas indicadas nos Programas experimentais (PARANÁ, 1950), anteriormente descritas, esta ideia estava implícita uma vez que as atividades que envolviam as situações cotidianas vivenciadas pelos alunos possibilitavam compreender o significado do número e a sua utilidade. 


\section{$(\mathrm{cc})$ EY}

Felisberto (2019) sintetiza estas mudanças indicando que o concreto como um saber para ensinar, em tempo de predominância do método intuitivo, "cumpria a função de tornar observáveis os conceitos matemáticos, principalmente, por meio dos objetos" (2019, p. 165). Já na disseminação dos princípios da Pedagogia da Escola Nova, o concreto, não apenas atrelado aos objetos e materiais de ensino, mas também às situações vivenciadas e internalizadas pelos alunos, "possibilitava que a aprendizagem matemática no ensino primário se desse de modo contextualizado, ocorrendo por meio de atividades físicas e/ou mentais" (FELISBERTO, 2019, p. 166).

Na medida em que novas concepções sobre o ensino foram sendo apropriadas, os saberes profissionais dos professores foram se transformando. Assim, se no primeiro momento o professor deveria fazer uso dos materiais com a finalidade de demonstrar a "verdade ensinada", chamando a atenção dos alunos para observarem as relações matemáticas pela repetição, no segundo momento, com a disseminação das ideias da Pedagogia da Escola Nova, o professor primário deveria conduzir os alunos a descobrirem as relações matemáticas, por meio das atividades motivadas pelos objetos.

\section{CONSIDERAÇÕES FINAIS}

O estudo, partindo da ideia de que o uso de materiais concretos para ensinar Aritmética tratava-se de um saber profissional do professor primário, mostrou que este saber para ensinar articulava-se aos saberes $a$ ensinar e ocupava um espaço importante no ensino normal quando o assunto era Metodologia de Aritmética.

Constituindo o uso dos materiais concretos como um saber profissional do professor primário, foi possível identificar que ao longo das décadas analisadas este saber passou por transformações na medida em que as ideias da Pedagogia da Escola Nova foram sendo apropriadas na Escola de Professores de Curitiba.

Por fim, a escrita deste trabalho permite perceber que os saberes profissionais não estão dados ao pesquisador e nem sempre se encontram oficializados nas prescrições legais da formação de professores. Investigar estes saberes requer o cruzamento de diferentes fontes históricas para que seja possível reconstruir as práticas de ensino de tempos passados e desvendar os meandros dos consensos existentes. 


\section{REFERÊNCIAS}

BRASIL. Ministério da Educação e Saúde. $A$ Organização do Ensino Primário e Normal no Estado do Paraná. Rio de Janeiro/Brasil: INEP. Boletim n. 20, 1942. Disponível em: http://repositorio.ufsc.br/handle/123456789/104590. Acesso em: 06 mar. 2014.

CALKInS, N. A. Primeiras Lições de Coisas: Manual de ensino elementar para uso dos paes e professores. Tradução de Rui Barbosa. Rio de Janeiro. Ministério da Educação e Saúde. Vol. XIII, Tomo I. Obras completas. 1950.

FELISBERTO, L. G. S. A concepção de concreto na aritmética da escola primária do Paraná: (1901-1932). 2014. 107 f. Dissertação (Mestrado em Educação) - Pontifícia Universidade Católica do Paraná, Curitiba. Disponível em:

https://repositorio.ufsc.br/handle/123456789/161731. Acesso em: 10 jul. 2018.

FELISBERTO, L. G. S. A pedagogia da Escola Nova e a concepção de concreto: o ensino dos saberes elementares matemáticos no Paraná (1920-1960). 2019. 180 f. Tese (Doutorado em Educação) - Pontifícia Universidade Católica do Paraná, Curitiba, 2019. Disponível em: http://www.biblioteca.pucpr.br/pergamum/biblioteca/img.php?arquivo=/000073/00007337.pdf . Acesso em: 15 maio 2019.

FERNANDES, Z. Metodologia. Caderno. Escola de Professores. Curitiba, 1945.

HOFSTETTER, R.; SCHNEUWLY, B. Saberes: um tema central para as profissões do ensino e da formação. In: HOFSTETTER, R.; VALENTE, W. R. (org.). Saberes em (trans)formação: tema central da formação de professores. São Paulo: Livraria da Física, 2017.

JULIA, D. A cultura escolar como objeto histórico. Campinas, SP. SBHE/Editora Autores Associados. Revista Brasileira de História da Educação. n. 1, p. 9-43, jan/jun. 2001.

MIGUEL, M. E. B. A formação do professor e a organização social do trabalho. Curitiba: Editora UFPR, 1997.

MIGUEL, M. E. B. A reforma da Escola Nova no Paraná: as atuações de Lysímaco Ferreira da Costa e de Erasmo Pilotto. In: MIGUEL, M. E. B.; VIDAL, D. G.; ARAÚJO, J. C. S. (org.) Reformas Educacionais: As manifestações da Escola Nova no Brasil (1920 a 1946). EDUFE: Minas Gerais, 2011.

NICLEVES, A. A adição. In: O ENSINO. Methodologia da Matematica. Revista da Inspetoria Geral do Ensino do Paraná. Curitiba, ano 3, n. 2, p. 154-161, set. 1924. Disponível em: https://repositorio.ufsc.br/handle/123456789/105387 Acesso em: 10 out. 2018.

PARANÁ. Relatório do Inspetor Geral da Instrução Pública. Cesar Prieto Martinez. Curitiba: Typ. da Penitenciária do Estado, 1920. Disponível em: 


\section{$(\mathrm{cc})$ EY}

http://www.arquivopublico.pr.gov.br/arquivos/File/RelatoriosSecretarios/Ano1920MF N806.pdf.

Acesso em: 21 set. 2018.

PARANÁ. Programa dos Grupos Escolares do Estado do Paraná. Curitiba: Irmãos Guimarães e Cia., 1921. Disponível em: https://repositorio.ufsc.br/handle/123456789/105310. Acesso em: 08 mar. 2014.

PARANÁ. Bases Educativas para Organização da Nova Escola Normal Secundária do Paraná. 1923. Disponível em: https://repositorio.ufsc.br/xmlui/handle/123456789/123699. Acesso em: 08 mar. 2014.

PARANÁ. Regimento Interno e Programas para Grupos Escolares. Curitiba. Diretoria Geral da Instrução Pública, 1932. Disponível em: https://repositorio.ufsc.br/handle/123456789/104589. Acesso em: 08 mar. 2014.

PARANÁ. Mensagem do Interventor Manoel Ribas à Assembleia Legislativa do Estado do Paraná. Curitiba, 1 set. 1937. Disponível em: https://repositorio.ufsc.br/handle/123456789/136546. Acesso em: 10 out. 2018.

PARANÁ. Regimento Interno e Programa para Grupos Escolares. Decreto no 9593 de 26/02/1940. Curitiba. Diretoria Geral da Instrução Pública, 1940. Disponível em: https://repositorio.ufsc.br/handle/123456789/100110. Acesso em: 10 out. 2018.

PARANÁ. Anteprojeto da Lei Orgânica da Educação. Curitiba, 1949. Disponível em: https://repositorio.ufsc.br/handle/123456789/104272. Acesso em 08 out. 2018.

PARANÁ. Curso Primário. Programas Mínimos Experimentais para os Grupos Escolares. Curitiba: Imprensa Oficial do Estado, 1950. Disponível em: https://repositorio.ufsc.br/handle/123456789/117113. Acesso em 08 mar. 2014.

PIAGET, J. Psicologia e Pedagogia. In: MUNARI, A. Jean Piaget. Tradução e organização Daniele Saheb. Recife: Fundação Joaquim Nabuco, Editora Massangana, 2010.

PILOTTO, E. A educação no Paraná: Síntese sobre o ensino público elementar e médio. Rio de Janeiro: INEP, p. 130 1954. Disponível em: https://repositorio.ufsc.br/xmlui/handle/123456789/105388. Acesso em: 10 mar. 2014.

PINTO, N. B.; FELISBERTO, L. G. S. Aritmética Intuitiva: das Primeiras lições de coisas à legislação. Revista Diálogo Educacional, vol. 16, núm. 49, jul./set., 2016, pp. 567-588.

ROMANELLI, O. O. História da Educação no Brasil (1930/1973). 21 ed. Petrópolis/RJ: Vozes, 1998.

THORNDIKE, E. L. A nova metodologia da Aritmética. Porto Alegre: Livraria do Globo, 1936. Disponível em: https://repositorio.ufsc.br/handle/123456789/134890?show=full. Acesso em: 03 ago. 2015. 


\section{$(\mathrm{cc})$ EY}

TRINDADE, E. M. C.; ANDREAZZA, M. L. Cultura e educação no Paraná. Curitiba: Ed. da UFPR, 2001. 134 p.

VALENTE, W. R. O ensino intuitivo da Aritmética e as Cartas de Parker. In: V CONGRESSO BRASILEIRO DE HISTÓRIA DA EDUCAÇÃO. Anais [...]. São Cristóvão: Universidade

Federal de Sergipe; Aracaju: Universidade Tiradentes, 2008.

VALENTE, W. R. O saber profissional do professor que ensina matemática: o futuro do passado. Paradigma (MARACAY), V. extra 1, p. 190-201, 2018.

Recebido em: 16 de maio de 2019

Aceito em: 18 de novembro de 2019 